\title{
Research and practices of large composite external wall panels for energy saving prefabricated buildings
}

\author{
Yunxing Shi', Yangang Zhang, Kun Ni, Wei Liu, and Ye Luo \\ Technical Center, China State Construction Engineering Corporation, Beijing, 101300, China
}

\begin{abstract}
The production process and application of large composite external wall panels (composite panels for short) are introduced in this paper. Composite panels with both load bearing and thermal insulation were formed by pouring normal concrete (NC) and ceramsite foamed concrete (CFC) continuously according to particular technological requirements, which made two layers into a seamless whole. The layers of $\mathrm{NC}$ and $\mathrm{CFC}$ are for load bearing and thermal insulation respectively. The composite panels were manufactured in the scale of industrial production, and applied to several energy saving prefabricated buildings successively, instead of polystyrene sandwich composite panels (sandwich panel for short) as external wall panels. There are several obvious advantages of the composite panel over the sandwich panel or outer benzoic board. Firstly, it solved the problems of durability of polystyrene and the complex production process of the sandwich pane, the production process of the external wall was thus greatly simplified. In addition, the fire risk was much reduced.
\end{abstract}

\section{Introduction}

Nowadays efficient construction and green building are regarded as the development goals of the building industry in China, and a perfect combination of prefabricated construction with an energy saving system is considered an effective way to achieve the goal. However, the external wall thermal insulation in use popularly with outer benzoic board shows obvious shortcomings, such as flammable, poor durability and easy to become detached. Although a concrete sandwich slab with a core of EPS or XPS as insulation layer prefabricated in the concrete product plant gets over some defects of outer benzoic board system, it is still a complex process and durability problem as well. However, a large composite external wall panel, developed by the China State Construction Technical Centre, is a fundamental solution for the problems above. The composite panels were made of normal concrete (NC) and ceramsite foamed concrete (CFC) with a continuous pouring process to achieve a seamless interface of two layers. The former is for load bearing, and the latter for thermal insulation respectively. An illustration of a full size composite panel in practical application is shown in Fig.1.

The composite panel has good thermal insulation due to a network of closed fine pores of the CFC layer, and its outer surface has architectural decoration as well as a water proof effect. Other decorative facade to imitate stone texture, wood grain and brickwork and so on are also available.

\section{Preparation of concrete production of composite panel}

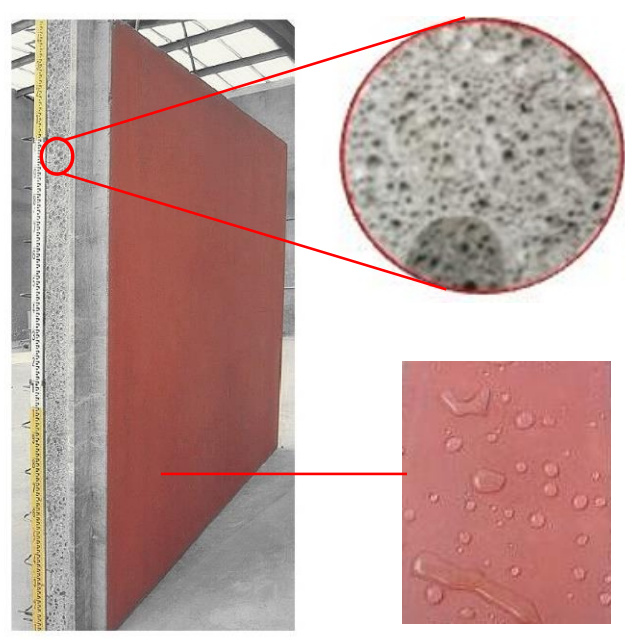

Fig.1 Appearance of the composite panel

\subsection{Preparation of concrete}

The NC was used for the load bearing layer, the strength grade of which should meet requirement of design, C30 C40 in general, according to Chinese standards. The fresh state of concrete should show good workability to avoid segregation and bleeding, so as to ensure a firm combination between $\mathrm{NC}$ and CFC layers.

* Corresponding author: yunxing_shi@sina.com 
The basic mix proportions of the CFC are given in Table1, in some cases, the proportions may need to be modified in a small range considering the situations of raw materials. As lightweight coarse aggregate of $\mathrm{CFC}$, a kind of sintered expanded clay ceramsite with average size $20 \mathrm{~mm}$ was used (as shown in Fig.2), and preformed foam from a large capacity foaming machine, developed by the Technical Center of CSCEC, was added to the mixing chamber directly (as shown in Fig.3), then mixed with the concrete mixture until a uniform state was reached in 30 60sec. Some losses of foam volume may occur during the mixing. The fresh $\mathrm{CFC}$ with stability foam showed a slump flow 450 500mm (as shown in Fig.4).

Table 1. Mix proportions of CFC $\left(\mathrm{kg} / \mathrm{m}^{3}\right)$

\begin{tabular}{|c|c|}
\hline Cement (P.O 42.5) & $280 \sim 330$ \\
\hline Fly ash ( II ) & $50 \sim 90$ \\
\hline $\begin{array}{c}\text { Ceramsite bulk } \\
\text { volume }\left(\mathrm{m}^{3}\right)\end{array}$ & $0.4 \sim 0.55$ \\
\hline Foam volume $\left(\mathrm{m}^{3}\right)$ & $0.45 \sim 0.6$ \\
\hline Water & $105 \sim 125$ \\
\hline Superplasticizer & (polycarboxylic liquid) 2 3.5 \\
\hline
\end{tabular}

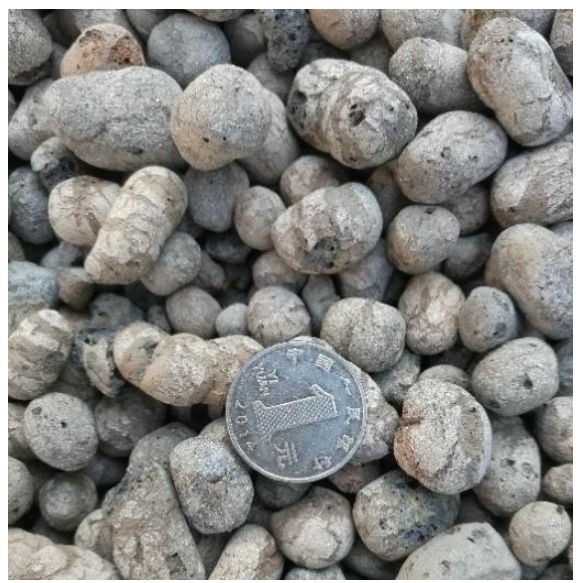

Fig.2 Appearance of expanded clay ceramsite

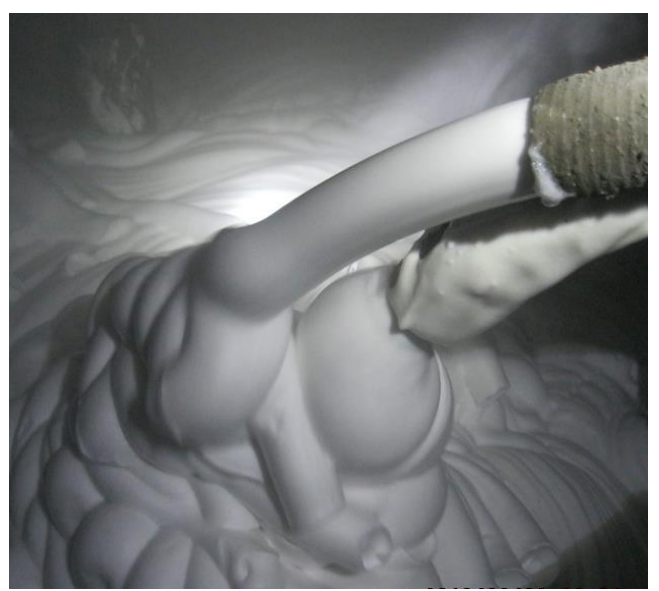

Fig.3 Preformed foam to the mixing chamber

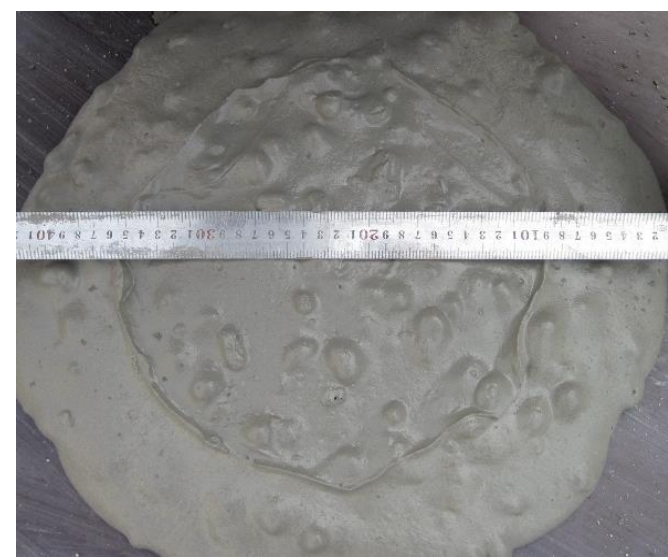

Fig.4 Slump flow of fresh CFC

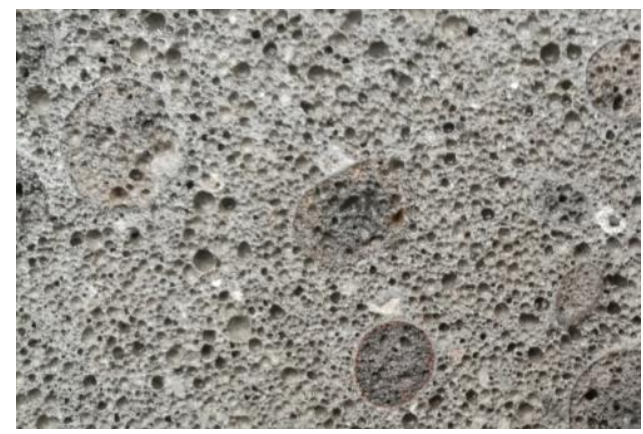

Fig.5 Morphology of internal pores of CFC

Fig. 5 is an observation of internal morphology of the hardened CFC; from the image of section, it could be seen that enormous numbers of closed pores were present in uniform distribution inside, whose most probable value of size was about $1 \mathrm{~mm}$. This was the reason why the composite panel showed sound performance of thermal insulation.

\subsection{Production of the composite panel and its thermal insulation}

In automatic production lines, the composite panel series have realized industrial scale production. The production flowchart is shown in Fig.6, among all of the operations mentioned in the flowchart, formwork, reinforcement work and concrete work were the major steps, moreover, concrete work was done after the reinforcement work, which was arranged according to the structural load and the codes concerning structural design. The concrete work consists of two parts, namely, pouring of $\mathrm{NC}$ and $\mathrm{CFC}$ in turn. Besides, for avoiding crack appearance along the connection of the two layers in the longitudinal direction, the time interval between the two pours is as small as possible, less than 40 minutes usually. A prolonged time interval may cause a negative effect for the combination between the NC and CFC layers. Of course, the workability of fresh concretes of $\mathrm{NC}$ and CFC need to be in a good phase, without segregation and bleeding, specially, the distributed foam in the fresh CFC ought to be kept in a uniform and stable state until final setting. 
Fig.7 is the appearance of the reinforcement cage with lifting lug after completion of the NC pour, one of the steps of process operation in the production line. Fig. 8 and Fig.9 show pouring the CFC and the composite panel in the demoulding operation respectively.

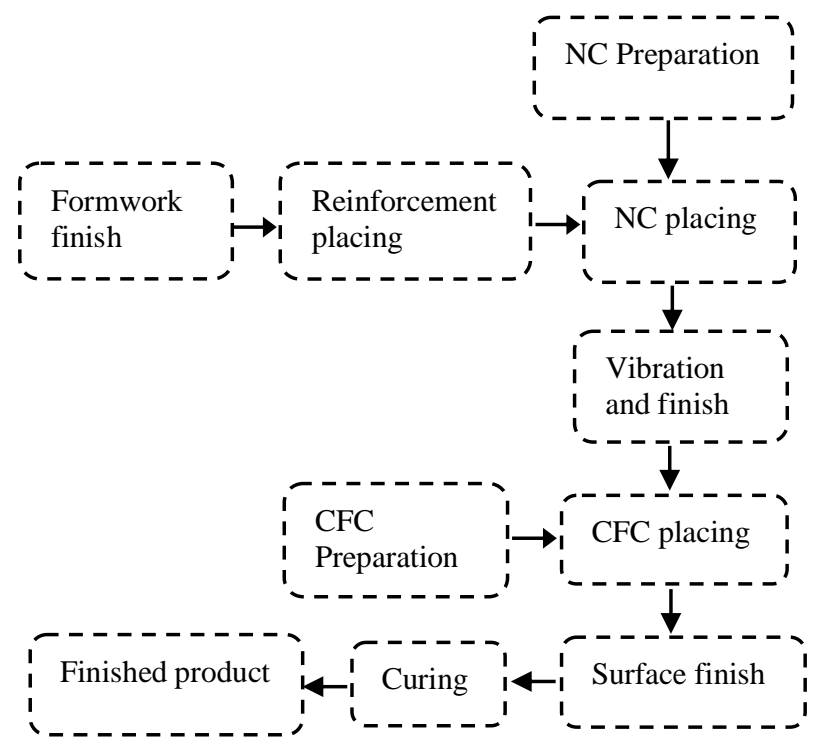

Fig.6 Production flowchart of the composite panel

The measured values of heat transfer coefficient of composite panels in different thickness are shown in Table 2. The performance of the thermal insulation of the composite panels could be changed by adjusting density and thickness of the CFC layer to satisfy the requirements of practical engineering.

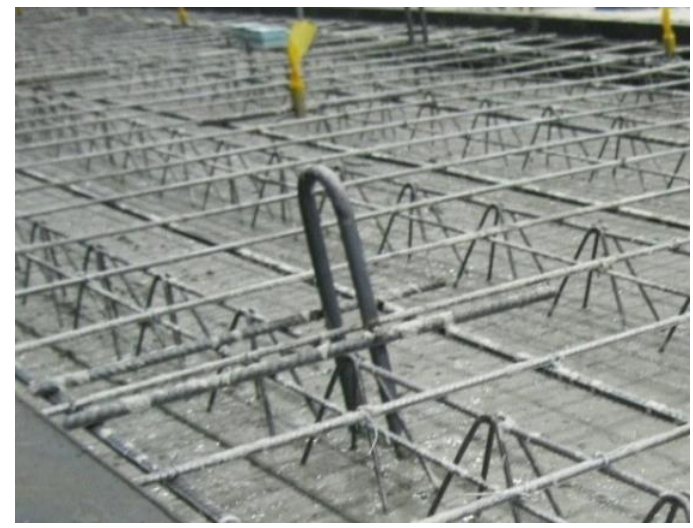

Fig.7 Reinforcement cage after completion of the NC layer.

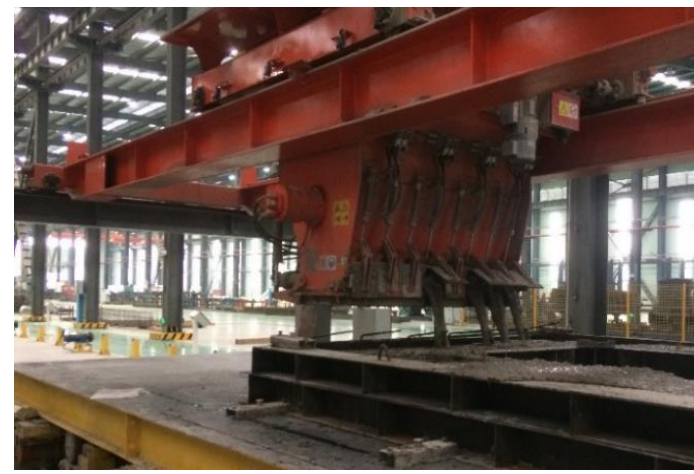

Fig.8 Operation of pouring CFC

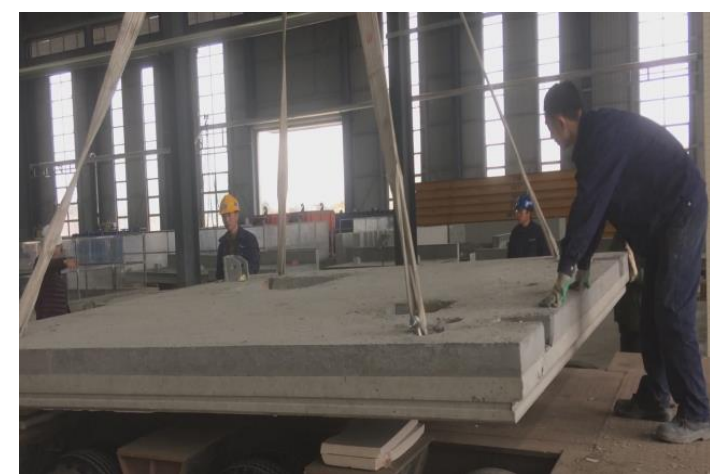

Fig.9 Composite panel in demoulding operation

Table 2. Heat transfer coefficient of the composite panel

\begin{tabular}{|c|c|c|}
\hline $\begin{array}{c}\text { Thickness of } \\
\text { RC }(\mathrm{mm})\end{array}$ & $\begin{array}{c}\text { Thickness of } \\
\text { CFC }(\mathrm{mm})\end{array}$ & $\begin{array}{c}\text { Heat transfer } \\
\text { coefficient } \\
\left(\mathrm{W} / \mathrm{m}^{2} \cdot \mathrm{k}\right)\end{array}$ \\
\hline 60 & 100 & 1.0 \\
\hline 60 & 150 & 0.737 \\
\hline 60 & 180 & 0.7 \\
\hline
\end{tabular}

\section{Examples of engineering application}

The composite panels have been successfully applied in four demonstration projects, which are all energy saving prefabricated buildings. The construction efficiency was greatly raised, and the energy saving effect was effectively improved as well due to the advantages of composite panels prefabricated in an industrialized scale.

\subsection{Demonstration project of an office building with green construction in Chengdu}

The project was located in the capital city of Sichuan province, Chengdu, Southwest China. The production date of the composite panels was from Nov.2016 to Feb.2017, and the assembling construction date was from Mar. to May of 2017. The sum of area of the composite panels applied in the project was over $3000 \mathrm{~m}^{2}$.

Erection construction was the next important stage of construction after completion of production of the composite panels. Fig.10 is the appearance inside of composite panels fixed to the $\mathrm{RC}$ frame structure on its facade by bolted connection.

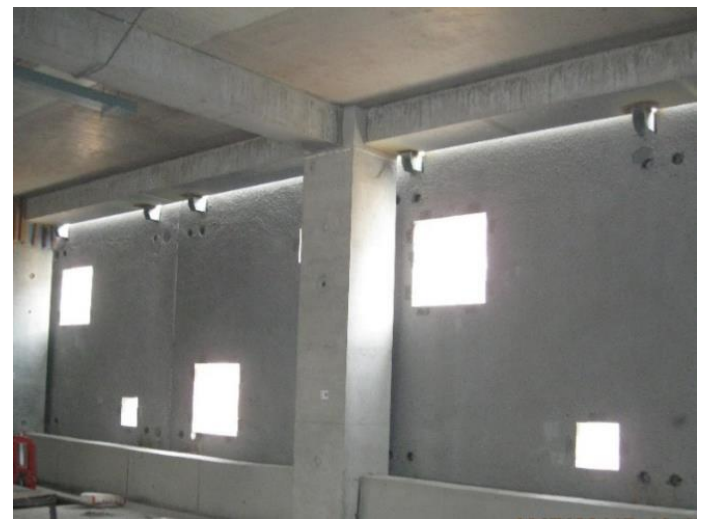

Fig.10 Composite panel on frame structure inside 
The building was finished after 3 months and Fig. 11 is a view of the outside of the building.

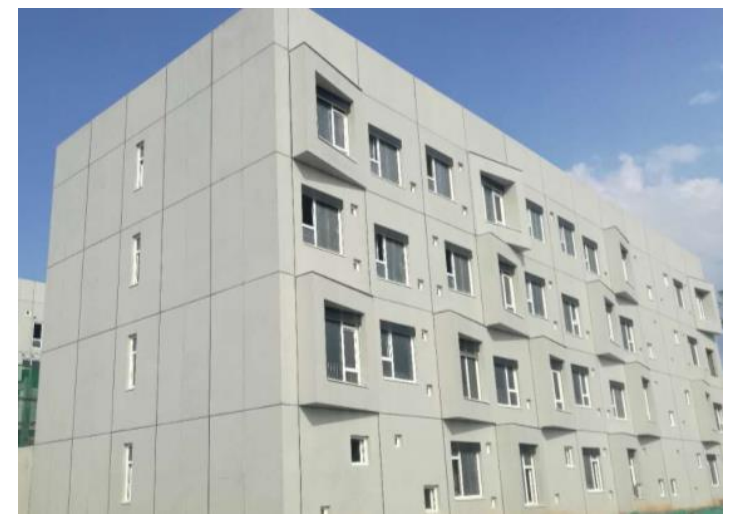

Fig.11 The outdoor scene of the building completed

\subsection{The other three demonstration projects}

After the first demonstration project in Chengdu, three other projects were also finished successively. They were located in Fuzhou city in East China, Changsha city and Wuhan city in Central China respectively. Among them, the appearances of two projects, in Fuzhou as well as in Wuhan, are shown in Fig.12 and Fig.13 separately.

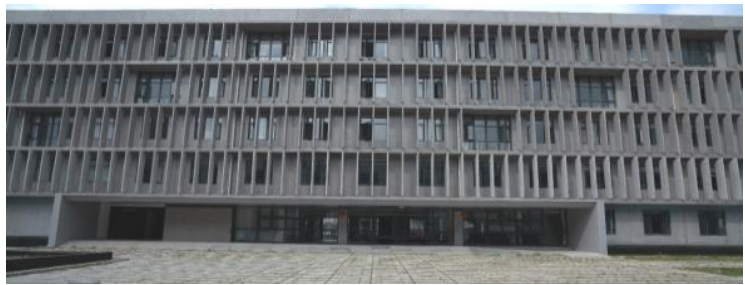

Fig.12 The building in Fuzhou after major structure completed

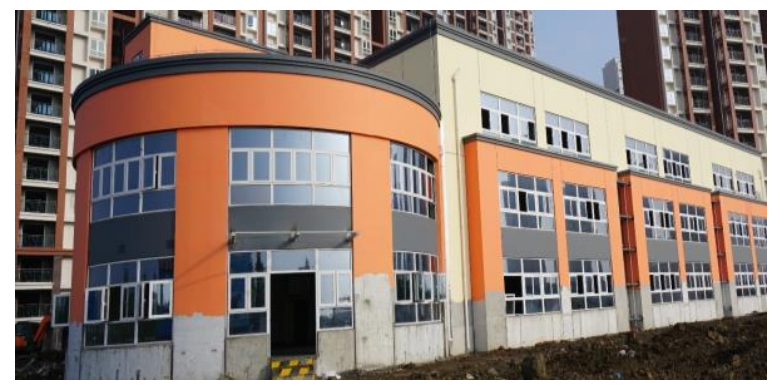

Fig.13 The building in Wuhan

\subsection{Another project under construction}

Besides the four projects completed above, another project under construction is a luxurious hotel for VIP guests (Fig.14), which is one of a collection of projects for the Winter Olympic Games to be held in Beijing and Zhangjiakou city in the winter of 2022 simultaneously. The project is located in the Chongli playing area in Zhangjiakou city. The thermal insulation external wall together with high fidelity stone facade was required by the design.

Additionally, agreeably to the design and green construction code, the sand and stone excavated in the construction site would be used as raw materials of the external wall as much as possible. The mass of mixture of sand and stone excavated out in the construction site is shown in Fig.15. The stone blocks accumulated are a kind of coarse-grained granite containing a part of sand gravel caused by weathering of rock. The sand and stone blocks after the treatment would be used as raw materials in the production of external walls. Fig.16 is a demonstrated panel of the prefabricated external wall for the project following the requirement of design. The external wall comprises a CFC main body for thermal insulation and a surface layer for decoration, moreover, the surface layer was made with a high-fidelity texture of the stone from the site, as shown in Fig. 16.

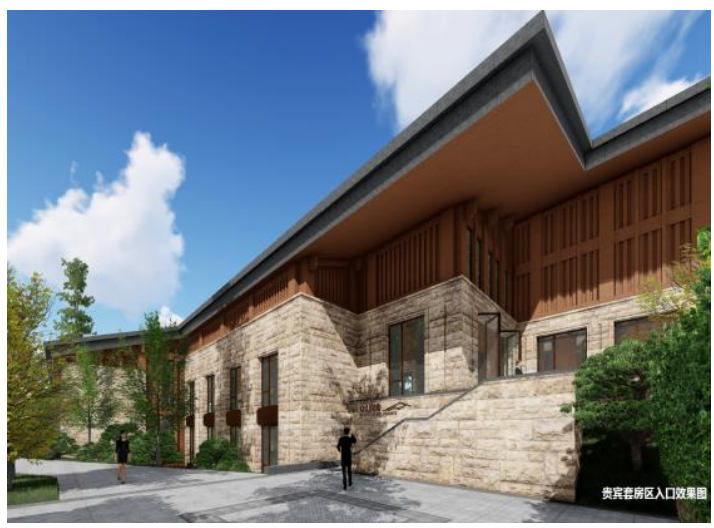

Fig.14 The appearance of the hotel in the design drawing

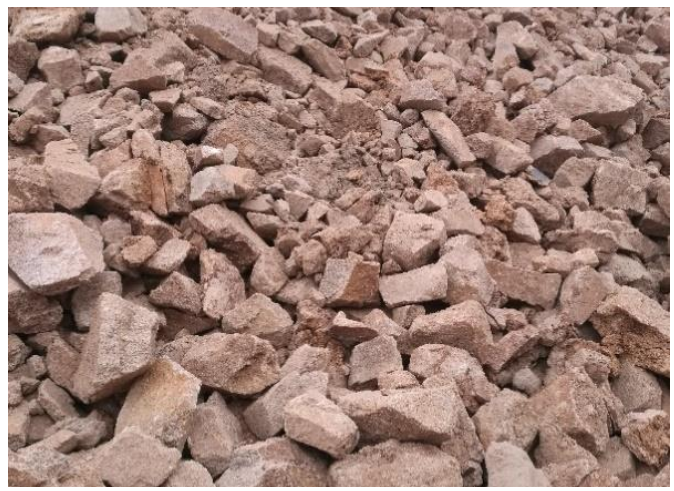

Fig.15 Sand and stone excavated out in the site

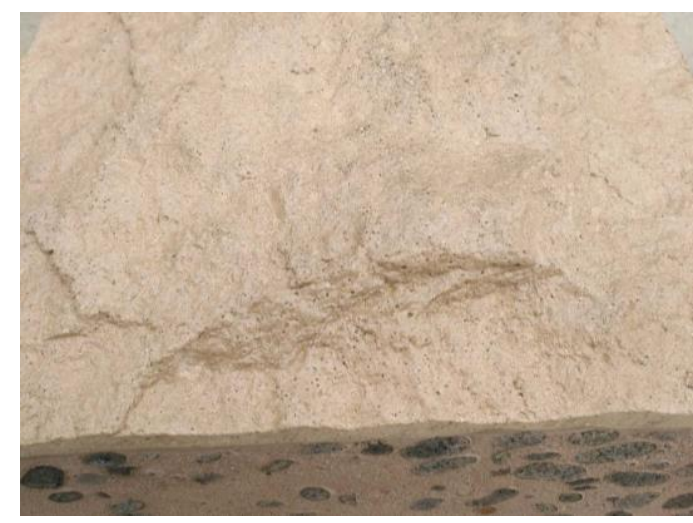

Fig.16 Demonstrated panel for the external wall

At the present time, large composite panels consistent with the demonstrated panel are on their way to 
production on an industrialized scale. It may be expected that such an enclosure structure with integration of thermal insulation and decoration will give the project plenty of advantages in green features and building energy saving.

\section{Concluding remarks}

1. The large composite external wall panels with integration of thermal insulation and decoration were prefabricated in a process of continuous pouring of $\mathrm{NC}$ and $\mathrm{CFC}$ in turn on a scale of industrial production. Moreover, large numbers of composite panels have been applied to several energy saving projects successfully.

2. The composite panels and their application in engineering showed the remarkable advantages of the production process, assembling construction, durability and building energy saving.

3. Sand, stone and raw soil excavated out in the site could be used as constituent materials of the composite panels. It has shown obvious benefit of resource saving and ecosystem protection.

\section{References}

1. Hubert Bachmann, Alfred Steinle, Precast Concrete Structures, Ernst \& Sohn, 2011,Berlin, Germany

2. Yunxing Shi, Lihong Jiang, Zhongnan Song, Ceramsite foamed concrete and its application in energy saving buildings, China Building Materials Press, Beijing, China (in print)

3. Yunxing Shi, Yangang Zhang, et al, An engineering example of energy saving renovation of external wall of original building with lightweight insulation composite panel, Proceedings of Concrete Solutions 6th International Conference on Concrete Repair, Taylor and Francis, June 2016, Thessaloniki, Greece

4. Yunxing Shi, Zhongnan Song, Yangang Zhang, et al, A new type of integrative composite panel with energy saving and decoration, China Invention Patent (Number CHINA: ZL201210489490.7) 2012 (in Chinese). 